\title{
El adiós al Swift y Armour: crisis y respuestas de los sindicatos friyeros del Cerro frente al cierre de los frigoríficos ${ }^{1}$
}

\author{
Goodbye to Swift and Armor: crisis and responses of the \\ friyeros unions of Cerro against the closure of the frigorificos
}

Lucia Siola Poggi

Universidad de la República

DOI: https://doi.org/10.25032/crh.v5i9.12

Recibido: 1/05/2019

Aprobado:08/10/2019

Resumen. El presente artículo aborda el cierre, hacia fines de 1957, de dos grandes fábricas frigoríficas ubicadas en el Cerro de Montevideo: los frigoríficos de capitales norteamericanos Swift y Armour. Considerando la centralidad del trabajo en la articulación de la sociabilidad, se traza un breve recorrido que muestra algunos aspectos de la crisis y reestructuración de la industria, y cómo estos fueron abordados por los trabajadores y sus organizaciones sindicales. En este sentido, se analizan las características de la crisis de la industria frigorífica, así como las acciones, debates y las tensiones protagonizadas por las organizaciones sindicales nucleadas en la Federación Obrera de la Industria de la Carne y Afines (FOICA) Autónoma, y su vínculo con otros actores de la realidad nacional del momento.

Palabras claves: Swift, Armour, sindicatos, industria frigorífica.

Abstract. This article addresses the closure, towards the end of 1957, of two large meatpacking plants located in the Cerro de Montevideo: the American capital Swift and Armour plants. Considering the centrality of work in the articulation of sociability,

$1 \mathrm{El}$ presente artículo forma parte de un proceso de investigación en curso, en el proyecto CSIC I+D denominado“El Cerro en los años sesenta (1957-1973), ¿barrio de trabajadores o comunidad obrera?”, coordinado por el Dr. Rodolfo Porrini. 
a brief route is drawn that shows some aspects of how the crisis and the restructuring of the industry, and how these were approached by the workers and their trade union organizations. In this sense, the characteristics of the refrigeration industry crisis are analyzed, as well as the actions, deliberations and tensions led by trade union organizations nucleated in the Workers' Federation of the Meat and Allied Industries (Federación Obrera de la Industria de la Carne y Afines, FOICA) Autonomous, and its link with other actors of the national reality of the moment.

Keywords: Swift, Armour, unions, meatpacking industry.

\section{Introducción}

El Uruguay de fines de la década de los cincuenta presenta un escenario convulsivo. La relativa expansión económica de los años cuarenta y el proceso de industrialización por sustitución de importaciones encontraban su límite objetivo con el fin de la segunda guerra y la reorganización del mercado mundial. Las condiciones económicas comenzaron a deteriorarse ya a inicios del decenio y con ellas las bases materiales que habían dado sustento a una política de arbitraje estatal en la relación capital - trabajo. De este modo, los instrumentos y las políticas de conciliación de clases fomentados por los gobiernos colorados de cuño batllista, enfrentaron nuevos problemas, y comenzaron a ser cuestionados desde diversos sectores políticos y sociales. La intervención de los trabajadores en el escenario nacional ante la pérdida de poder adquisitivo de los salarios y el cuestionamiento de sectores empresariales y del propio gobierno a ciertas reivindicaciones económicas y sociales logradas en el pasado, se hizo más sistemática a través de grandes conflictos protagonizados por las organizaciones sindicales. ${ }^{2}$ La novedad de la década es tal vez el aumento de medidas represivas y de reglamentación sindical que comenzaron a desenvolver los gobiernos frente a la creciente conflictividad obrera, incluyendo la puesta en práctica en 1952 de Medidas Prontas de Seguridad con las que "declaró ilícitas las huelgas, clausuró locales sindicales, detuvo y procesó dirigentes”3. Más allá de que luego estas medidas fueron

2 Ángel Cocchi, Ana Frega, Benjamín Nahum e Yvette Trochón. Historia Uruguaya tomo 9, crisis política y recuperación económica 1930-1958. (Montevideo: Ediciones Banda Oriental, 2011, 114).

3El gobierno comenzó a utilizar las Medidas Prontas de Seguridad según el inciso 17 del Artículo 168 de la Constitución. 
atenuadas o dejadas sin efecto, marcaron la tónica de un nuevo relacionamiento con el movimiento sindical.

El retorno al gobierno colegiado en 1954, como mecanismo de concertación política gubernamental de los ya fragmentados partidos del régimen, lejos de atenuar las divergencias en la conducción del Estado las hizo más evidentes con una serie de crisis políticas que dejaron en soledad en el Ejecutivo (Consejo Nacional de Gobierno) al coloradismo quincista. Así, su líder Luis Batlle Berres y el resto de los consejeros de su sector debieron gobernar los últimos años con un parlamento fuertemente opositor, que incluía al propio batllismo de la $14 .{ }^{4}$ Además del Partido Nacional encabezado por el herrerismo y reforzado hacia mediados de 1958 con el ingreso del sector ruralista de Benito Nardone, también desarrollaron durante todo el período duras críticas al gobierno los partidos de la izquierda, Comunista y Socialista, que participaban de la agitada movilización social. 5

Según Héctor Rodríguez la movilización sindical del período 1954-1958 fue muy significativa y masiva ${ }^{6}$, tanto en el sector industrial como en el agrícola, sufriendo en diversas ocasiones la represión patronal y estatal. Así, en los grandes conflictos de la industria que tienen lugar entre 1953 y 1956 (fábricas textiles, metalúrgicas, frigoríficos), mediante llamados publicados en la prensa las empresas contrataron nuevo personal para el funcionamiento de las fábricas, medidas que no eran cuestionadas por el Estado. Además, este intervenía con la policía en lo que denominaba "hechos de violencia" que se suscitaban con los nuevos trabajadores (contratados como mecanismo para quebrar las huelgas y a los que se permitía el porte de armas), y para reprimir las ocupaciones y movilizaciones obreras, así como las barriadas en las zonas donde se radicaban las fábricas.7 Así, en pocos años la lista de

\footnotetext{
4 Dentro del Partido Colorado, en el sector denominado batllista, se expresaron desde 1946 dos tendencias: la liderada por Luis Batlle Berres en torno a la lista 15, y la liderada por Lorenzo Batlle Pacheco, Cesar Batlle Pacheco y Rafael Batlle Pacheco en torno a la lista 14.

5 Nahum y otros 115-118.

6 Algunas de las más significativas: huelga textil de dos meses (1954-55), huelgas frigoríficas (1955, 1956, 1957), huelga metalúrgica (1955), huelga de Funsa (1956), de arroceros, tamberos, (1957), remolacheros, (1958), entre otras.

7 Por ejemplo, en 1953 en la fábrica La Mundial, la policía desalojó a los trabajadores que ocupaban la planta. En 1954 la huelga textil (que inició en un conflicto en la fábrica Pedro Sáenz del Cerro) fue reprimida en varias ocasiones por la policía, además de ingresaron a la industria más de 1000 trabajadores para sustituir a los huelguistas, según Héctor Rodríguez, Nuestros sindicatos. (Montevideo: Centro de Estudiantes de Derecho, 1966), 64-65.
} 
trabajadores y gremialistas asesinados por "rompehuelgas" se acrecentó: Antonio Gómez Delgado dirigente de la Unión Obrera Textil (1955), María del Carmen Díaz (vecina de la Teja y suegra de un gremialista) en el marco de la huelga de los metalúrgicos de Ferrosmalt (1955), Cesar Muñoz sindicalista de la Federación Obrera de la Carne (1956), ${ }^{8}$ entre otros. También se produjeron episodios de represión policial a la movilización social durante las marchas de los trabajadores frigoríficos (en octubre y noviembre de 1957) ${ }^{9}$ y en las primeras manifestaciones estudiantiles en el marco de la huelga por la Ley Orgánica.10

Los cambios políticos del período con el triunfo del Partido Nacional en las elecciones de 1958 por primera vez en 93 años, deben ser entendidos como parte de una dinámica compleja y contradictoria de estos años de crisis y transición, que de alguna manera muestran cierto revulsivo en los mecanismos de dominación política hasta ese momento consolidados.

Lo mismo parecería visualizarse -aunque es preciso profundizar las investigaciones en este campo- en la dinámica que presenta el movimiento obrero en estos años de extensas y duras huelgas. Un movimiento que se vio reforzado por el crecimiento numeroso de la clase obrera industrial ${ }^{11}$, por la creación de nuevas organizaciones sindicales y su coordinación -fomentadas por el aumento de la represión y de la conflictividad social-, que incluía también a numerosos sectores del funcionariado público.

De algún modo 1958 fue un año que condensó la conflictividad social, la movilización y las huelgas de todo el período, por la confluencia de numerosas luchas obreras, de sectores medios y estudiantiles. Estos conflictos permitieron un

\footnotetext{
Algo similar sucedió en 1955 en el conflicto metalúrgico de Ferrosmalt (abril- setiembre de 1955), donde la policía reprimió brutalmente y estableció prácticamente un "estado de sitio" en la barriada de La Teja, ver: Susana Dominzain, (coord.), Pablo Ferreira, Álvaro Sosa y Lorena García. Así se forjó la historia, acción sindical e identidad de los trabajadores metalúrgicos en Uruguay. (Montevideo: Editorial Primero de Mayo, 2006), 279.

8 También en dicha ocasión fue atacado de gravedad el huelguista Ricardo Espala, quién perdió el habla a causa de las heridas recibidas.

9 Diario El Popular, 13 de Abril de 1957, p 8.

10 Rodríguez, Nuestros sindicatos 72.

11 En 1955 la población obrera uruguaya era de 194.623 en un total de 2.630.00o habitantes. En Montevideo la relación era de 144 mil en 900 mil habitantes, es decir un 16\% de la población capitalina eran obreros industriales. Mientras que un año después, sobrepasaban los 150 mil, alcanzando a ocupar el 24\% de la población activa del país en esa rama, en: Cocchi y otros 154 .
} 
acercamiento entre diversas expresiones del movimiento sindical, que durante estos años se encontraban reagrupadas en la Unión General de Trabajadores (UGT) ${ }^{12}$, en conglomerado de gremios denominados 'autónomos', y en la Confederación Sindical del Uruguay (CSU) ${ }^{13}$,entre otras expresiones. Así surgieron acciones y huelgas solidarias con gremios en conflicto (paros de 24 horas), coordinaciones sindicales con participación de la Federación de Estudiantes Universitarios del Uruguay (FEUU) y diversas reuniones que buscaron consolidar de forma permanente ese trabajo común. ${ }^{14}$

El nuevo gobierno colegiado del Partido Nacional que asumió en marzo de 1959, profundizó las prácticas represivas antes mencionadas. En los primeros años, se acrecentó el actuar de grupos de rompehuelgas a veces vinculados al sindicalismo "amarillo" que actuaban en connivencia con los empresarios, el gobierno, y los emergentes grupos de ultraderecha. ${ }^{15}$

En este cuadro, el estudio de la comunidad obrera del Cerro ${ }^{16}$, un barrio ubicado en la zona oeste de Montevideo que contemplando un área amplia concentraba una población cercana a las 50 mil personas, ${ }^{17}$ con tres de las fábricas más grandes e importantes del país como lo eran los frigoríficos Swift, Armour y Nacional, nos

12 Fundada en 1942 como intento de unificación del movimiento sindical, fue perdiendo filiales, quedando reducida en la década de los cincuenta a los sindicatos de influencia comunista.

13 Confederación que nucleaba a diversos sindicatos del país, fundada en 1951 y afiliada a la Confederación Internacional de Organizaciones Sindicales Libres (CIOSL) y a la Organización Regional Interamericana de Trabajadores (ORIT). Si bien en sus comienzos había logrado agrupar a un conglomerado importante de sindicatos, hacia el período abordado en el presente artículo se evidenciaba su crisis y su deslegitimación en un amplio arco del movimiento sindical, catalogándola de "central amarilla".

14 Por ejemplo, en 1958 funcionó la Coordinadora Pro Central Única, y luego una Asamblea Consultiva Pro Central Única.

15 Susana Dominzaín (coord.), Pablo Ferreira, Álvaro Sosa y Lorena García, Así se forjó la historia, acción sindical e identidad de los trabajadores metalúrgicos en Uruguay. (Montevideo: Editorial Primero de Mayo, 2006), 235.

16 Cuando hacemos referencia al término comunidad obrera nos referimos exclusivamente a la perspectiva desarrollada por Eric Hobsbawm, en "El movimiento obrero en la gran ciudad", Política para una izquierda racional (Barcelona: Editorial Critica, 2016). La expresión es utilizada para describir una población de trabajadores radicada en las cercanías de las fábricas o centros de trabajo, que permite trasladarse a pie a esos establecimientos e incluso almorzar en el hogar, generando un tipo de sociabilidad particular. Somos conscientes que el término merece una mayor conceptualización y problematización a partir de las diversas interpretaciones y miradas que han emergido en distintos estudios, pero su desarrollo escapa al presente trabajo.

17 Los datos del Censo Nacional de población 1963 (el único realizado desde el de 1908) presentan el problema de que contemplan una zona más amplia que el Cerro. Establece así los siguientes datos: Cerro y Casabó un total de 35502 y Cerro Norte, La Paloma 11815, sumando ambas zonas da un total de 47317. (Censo 1963, Cuadro 1, Población por sexo, según sección censal y barrios.) 
permite visualizar a través de un caleidoscopio local algunos de los complejos problemas que hacían a la realidad política, social y económica del país, y viceversa.

Sumergirnos en la dinámica de esta población obrera del oeste capitalino, así como en sus organizaciones sindicales -durante este período- implica estudiar también las transformaciones y crisis de una de las más importantes comunidades obreras de nuestro país. En este sentido, es un elemento clave para comprender el proceso de conformación de la clase obrera montevideana y del sindicalismo uruguayo. Entendida esta a partir de la perspectiva de Edward Thompson (que entendemos retoma la visión clásica del marxismo) ${ }^{18}$, donde la clase se comprende no sólo por el lugar objetivo que las personas ocupan en el proceso de producción capitalista, sino también por el proceso concreto de experiencias y luchas en las que actúan. De este modo, el historiador británico ubica a la clase obrera en su dimensión histórica, no como una categoría estática o cosificada, sino como una relación construida y reconfigurada por los sujetos en el propio proceso de la lucha de clases que abarca las diversas dimensiones de lo humano. ${ }^{19}$

Lo mismo cabe señalar para la organización sindical, que como veremos se modifica y reconfigura en el tiempo frente a la dinámica de la lucha de clases, esto es, de un lado frente a procesos económicos y del otro a la propia intervención y acción de los sujetos y actores políticos.

En este sentido, el presente artículo contribuye a un primer acercamiento de una de las más importantes organizaciones obreras de la época (la Federación Obrera de la Industria de la Carne y Afines-Autónoma (FOICA-A), cuya sede central y principales sindicatos se encontraban ubicados en el Cerro.

Cabe señalar y precisar, que lo que pretendemos historiar aquí es el modo en que la crisis general que azotaba al país se expresaba en la barriada obrera del Cerro, más las consecuencias que estos problemas ocasionaron en la vida gremial de los

18 Lucas Poy, Los orígenes de la clase obrera argentina, huelgas, sociedades de resistencia y militancia política en Buenos Aires, 1988-1896. (Buenos Aires: Imago Mundi, 2014, 37).

19 E.P Thompson, La formación histórica de la clase obrera, Inglaterra 1780-1832, tomo I. (Barcelona: Editorial Laia, 1977). 
sindicatos friyeros. ${ }^{20}$ Para lo cual abordamos la dinámica del conflicto desatado por el cierre y reapertura de las fábricas y mostramos cómo este proceso modificó la subjetividad obrera, generó diversas miradas y propuestas sobre la problemática y llevó a la división de las organizaciones sindicales cerrenses. Intentamos de esta forma dejar de manifiesto la relación dialéctica entre el ser social y la conciencia, a partir de desenvolver aspectos de lo que Thompson establece conceptualmente como "experiencia". Como recuerda Pablo Alvira, para Thompson la experiencia "cambia con los cambios del ser social y [en palabras del historiador inglés] 'es determinante, en el sentido en que ejerce presiones sobre la conciencia social existente' [...]". ${ }^{21}$

El período que aborda el trabajo corresponde al conflicto que tiene lugar entre 1957 y 1961, que es sólo el inicio de un proceso que se extiende por más de una década donde las organizaciones obreras enfrentan una reorganización capitalista de la industria frigorífica.

\section{El Cerro como barrio obrero capitalino; su espacio geográfico y urbano}

El espacio geográfico cerrense en estos años, con sus diversas fronteras, se expandía desde la bahía de Montevideo y el Río de la Plata, hasta el límite establecido por el arroyo Pantanoso. El barrio aparecía como un enclave distanciado y en algún punto aislado naturalmente del resto del territorio capitalino, configurando un espacio local con ciertas características autónomas. Dentro de estos límites naturales, el barrio se construyó con calles ortogonales en referencia a su arteria principal, la calle Grecia, que atravesaba de punta a punta el barrio y constituía el centro de su actividad, en la cual se ubicaban los principales comercios y sedes político-culturales.

Teatros, cines, clubes, estadios, boliches y playas ubicados en el barrio, constituían los lugares de esparcimiento y de uso del tiempo libre de las familias obreras. Además de las numerosas asociaciones (gremiales, barriales, coorporativas, de inmigrantes) en las cuales también se desarrollaba la sociabilidad obrera.

20 Término que alude al trabajador de los frigoríficos, utilizado tanto por ellos mismos como por su entorno.

21 Pablo Alvira, “¿Historia vs. Teoría? Epistemología y Ciencia Histórica en la Polémica ThompsonAlthusser”, Revista Historia Actual. 8 (2010), 145. 
El espacio urbano del Cerro también se distinguía y diferenciaba del resto de los barrios montevideanos por la composición de su población. En sus orígenes, la zona fue destino de la inmigración europea, concentrando a numerosas familias y comunidades que se instalaron en las cercanías de las fábricas, aportando en la construcción de lo que inicialmente fue denominado como Villa Cosmópolis. La nomenclatura particular de las calles cerrenses, con nombres de países y ciudades puede visualizarse como una pretensión de integración de las múltiples nacionalidades, culturas e idiomas, que se relacionaban con la población del Cerro y la clase obrera local.

\section{Las fábricas del Chilled y el Corned Beef}

En el Cerro se concentraba una gran actividad industrial. Allí se erigían tres inmensas fábricas, grandes edificios de cemento con altas chimeneas. Por sus instalaciones pasaban cotidianamente miles de reses, hombres y mujeres. En aquellos lugares sonaban asiduamente sirenas anunciando el inicio y el fin de la jornada, así como los cambios de turno; entraban y salían camiones, a veces con animales, a veces con mercaderías; había una actividad constante todo el día desde el amanecer. Los frigoríficos Artigas, Swift (de capitales norteamericanos) y Nacional (de capitales nacionales mixto público-privado), eran el gran motor de la zona. Se estima que entre los tres empleaban en los momentos de mayor actividad, entre 8 mil y 10 mil trabajadores, los que daban al barrio una fisonomía proletaria.

Las industrias frigoríficas se instalaron en Uruguay en las primeras décadas del siglo XX. Al igual que sus antecesores en el rubro de la carne, vieron en el Cerro de Montevideo buenas condiciones para desenvolver su producción, incluso se asentaron sobre las instalaciones de los saladeros. Así, en el ex saladero Cibils, el 15 de octubre de 1912 inició sus operaciones el Frigorífico Montevideo, que en setiembre de 1916 se convirtió en el Frigorífico Swift de Montevideo. Esta compañía de capitales estadounidenses se ubicó frente a la bahía denominada Punta de Lobos, ocupando unas 170 hectáreas de propiedad. ${ }^{22}$

22 Aníbal Barrios Pintos y Washington Reyes Abadie. Los barrios de Montevideo, El Cerro, Pueblo Victoria (La Teja) y barrios aledaños. (Montevideo: IMM, 1994), 68. 
Poco después, en octubre de 1917 en el ex Saladero Tejera se instaló el Frigorífico Artigas propiedad de una Sociedad Anónima de capitales nacionales, adquirida al poco tiempo por la firma estadounidense Armour y Cía. ${ }^{23}$ Ambas firmas con sede en Chicago, eran parte de grandes monopolios que contaban con diversas filiales en América Latina y el mundo. En la década del cincuenta estas corporaciones ceden sus filiales rioplatenses al grupo International Packers Ltd. (un grupo financiero con sede en Londres). ${ }^{24}$

El 6 de setiembre de 1928, por la Ley 8282, fue creado como Ente Testigo el Frigorífico Nacional. Su rol era de contralor de la industria y el comercio de carnes, además de tener bajo su responsabilidad el abastecimiento del mercado interno de Montevideo, para lo cual tenía el monopolio de la faena. Se instaló en la zona que actualmente se denomina Puntas de Sayago, en la antigua planta saladera de Sansinena, ${ }^{25}$ e inició su actividad el 30 de junio de $1929 .{ }^{26}$

Según Mirta Zaida Lobato, las grandes fábricas frigoríficas se instalaron a las orillas del Río de la Plata y sus afluentes, porque necesitaban de grandes extensiones para ubicar los corrales y los edificios, pero fundamentalmente porque precisaban de los cursos de agua para sus procesos productivos y para la construcción de embarcaderos. ${ }^{27}$ Contar con un puerto cercano tenía relevancia como mecanismo para abaratar costos de transporte y efectuar un rápido traslado de los productos a los centros de consumo. 28

El Cerro como zona capitalina y por sus particularidades geográficas reunía todas estas condiciones que hicieron propicia la actividad frigorífica y con ella, la conformación de una gran comunidad obrera, que se fue desarrollando a partir del

23 Barrios Pintos y Reyes Abadie68.

24 Martín Buxedas. La industria frigorífica en el Río de la Plata. (Buenos Aires: CLACSO, 1983), 24. 25 Que funcionó desde 1911 donde había funcionado la Frigorífica Uruguaya a partir de 1902. 26 Barrios Pintos y Reyes Abadie 69.

27 Según José Pedro Malagraba, el agua corriente casi no alcanzaba para las necesidades de la producción, por lo cual la fábrica Swift construyó canales de hormigón en la ladera del Cerro para almacenar agua del Río de la Plata que se filtraba y cloraba para el lavado de la fábrica. También construyó Tajamares en los techos para almacenar agua de lluvia. En Mi vida. 68 años ininterrumpidos en la Industria (1925-1993) un ejemplo de "SelfMade Man" (Montevideo: Impresos Vanni, s.f,) 49.

28 Mirta Zaida Lobato, La vida en las fábricas: trabajo, protesta y política en una comunidad obrera, Berisso (1904-1970). (Buenos Aires: Editorial Prometeo, 200), 80. 
asentamiento en las zonas aledañas de las fábricas (saladeros primero, frigoríficos después), de miles de familias que con su acción fueron dándole forma al barrio.

El trabajo fabril se constituyó en un articulador central del barrio ${ }^{29}$, y con él surgió una sociabilidad obrera particular, atravesada de multiplicidad de culturas que fueron confluyendo en la construcción de una cultura y una identidad propia; la cerrense. Esta no estuvo exenta de contradicciones, pero estuvo marcada por un fuerte contenido de clase y una ferviente actividad gremial, en cuyo centro se encontró a partir de 1943 la Federación Obrera de la Industria de la Carne y Afines (Autónoma), (FOICAA).

\section{El trabajo en la fábrica}

Las fábricas del frigorífico Swift, Artigas (Armour y Cía), Nacional y Anglo3o, constituían en nuestro período un tipo de industria de manufactura que fue denominada como tradicional, compartiendo sus establecimientos similitudes en la organización del trabajo, así como en los procesos productivos y las mercaderías producidas. Esta industria frigorífica (que fue sufriendo transformaciones a lo largo de las décadas) no solo se caracterizaba por la faena de ganado, la venta de carne congelada, y la elaboración de carnes enlatadas, sino que realizaba un procesamiento integral de todo el animal, aprovechando e industrializando también lo que se llamó subproductos (hueso, grasa, sebo, sangre, cueros, desechos, etc). Además, estas inmensas fábricas utilizaban la capacidad de su conserva ${ }^{31}$ para el procesamiento y el enlatado de diversas frutas y verduras ampliando el rubro de su producción, que junto al de los subproductos le daba a estás fábricas un carácter más general de industria manufacturera de la alimentación.

\footnotetext{
29 No desconocemos las diversas formas de trabajo que existían en la barriada cerrense, incluyendo los comercios y servicios, el trabajo a domicilio, o el trabajo doméstico que realizaban miles de mujeres, pero consideramos al trabajo fabril como central en la articulación del barrio.

3o Ubicado en la ciudad de Fray Bentos, en el Departamento de Río Negro, en las instalaciones de la ex - fábrica de extracto de carne Liebig's, adquirida en 1924 por la firma Anglo. S. A del grupo de capitales ingleses Verstey.

31 El departamento de Conservas, era el área donde funcionaban las secciones que preparaban las carnes para conservas y se enlataban.
} 
En la sección conserva de los Frigoríficos Nacional, Swift y Artigas, además de los extractos de carne y la carne enlatada (el famoso CornedBeef), se industrializaba una gran cantidad de frutas y legumbres.

Otra particularidad de este tipo de industrias era que el proceso productivo abarcaba todos los aspectos de la manufactura. La mercadería pronta para su venta era luego embarcada en los muelles de las fábricas y transportada para la exportación hacia el Hangar 10 del Puerto, en el caso de Swift y Artigas.

Los frigoríficos estadounidenses ocupaban predios que abarcaban varias manzanas, en dos extremos del barrio: uno sobre el Pantanoso y el otro sobre la bahía del Río de la Plata. Se trataban de fábricas de enormes dimensiones y sus instalaciones contaban con edificios de varias plantas, que se conectaban unos a otros a través de puentes y pasajes. Contaban además con calles internas por las cuales se transitaba hacia las diversas construcciones ocupadas por oficinas, galpones, el embarcadero y los corrales.

Los procesos productivos y la organización del trabajo eran similares en ambas plantas, aunque la magnitud de la fábrica Swift era más importante en cuanto a su dimensión y capacidad. Según afirma O' Leary "los tres frigoríficos extranjeros que controlaban el mercado (Swift, Artigas y Anglo), se instalaron como dependencias de su casa matriz, reproduciendo sus procesos de producción y las formas de gerenciamiento" ${ }^{32}$ Lobato afirma lo mismo para las fábricas Swift y Armour ubicadas en Berisso-Argentina- y puntualiza que estas utilizaban el modelo taylorista de planificación, eficiencia y racionalidad. 33 En el caso de los frigoríficos de capitales estadounidenses ubicados en el Cerro de Montevideo, la organización productiva de las plantas y del trabajo en las secciones, es coincidente con lo que remarcan las autoras antes mencionadas.

El trabajo en las fábricas era agotador. El sistema concentraba cientos de personas en una sección y muchas de ellas en torno a una línea de producción,

32 John O'Leary, “Employers and Industrial Relations in the Australian Meat Processing Industry: an Historical Analysis", Tesis de Doctorado, School of Organisation and Management, Faculty of Business, University of New South Wales, 2008; citado en:María Magdalena Camou,"Estancamiento productivo y relaciones de trabajo en el Frigorífico Swift de Montevideo, 1911- 1957", Boletín de Historia Económica. 9 (2010), 24.

33 Lobato $75-76$. 
trabajando horas de pie realizando tareas monótonas, con una estricta supervisión y vigilancia del proceso productivo. Si bien el proceso de trabajo se encontraba mecanizado, parte importante del mismo dependía de la fuerza y de la actividad humana. Por esa razón la empresa buscaba evitar y/o acortar todo lo posible los tiempos muertos, lo que llevaba en muchas ocasiones al maltrato y abuso de los capataces y supervisores, 34 así como a un fenomenal desgaste físico del personal. La supervisión también actuaba como mecanismo de control y represión para el manejo de la sociabilidad obrera dentro de la fábrica, así como para asegurar el estricto tratamiento de la mercadería. Se reprimía y sancionaba la ingesta y el uso de la mercadería, además de los robos, que según testimonios en muchas ocasiones sucedían como mecanismo de desquite por parte de los trabajadores frente a la explotación sufrida desde las empresas.

Los ritmos de trabajo, en muchos casos dependían del esfuerzo manual del trabajador (sobre todo en las primeras secciones del proceso productivo como la matanza) y en algunos casos, eran marcados por la mecanización en función del ritmo de la 'noria' o 'trolley'. Del ritmo de las secciones que constituían las etapas iniciales del proceso (matanza, desollado, vísceras y congelado), dependía el funcionamiento del resto de la planta, 35 que, según un remitido de prensa de la Federación Autónoma de la Carne, era un trabajo más acelerado que en general no superaban las 4 o 5 horas diarias y concentraba a los trabajadores más especializados, mayoritariamente hombres. ${ }^{36}$

Según aparece asiduamente en los testimonios, el ingreso a la fábrica se daba a partir de edades tempranas que iban desde los 13 a 18 años, en muchos casos por recomendaciones de familiares que trabajaban en los establecimientos. Si bien, la mayoría de las tareas precisaban de un aprendizaje previo y en algunos casos puntuales constituían prácticamente un oficio, en general tenían baja dificultad. Esto permitió la rotación del personal en diversas secciones en función de las necesidades productivas,

34 Entrevista a Eva Luna, obrera del frigorífico Artigas durante EFCSA, realizada por Lucía Siola y Alesandra Martínez, Montevideo, 20 de setiembre de 2018.

35 Camou 26

36 Declaración de la FOICA -A, publicada en el periódico El Bien Público, 7 de junio de 1956, en Juan Pablo Gonetti, La Marcha del Hambre, ¿Una historia enterrada, silenciada o escondida?,(Uruguay: Tradinco. S.A, 2006), 106. 
un mecanismo muy utilizado por estas empresas. 37 El sistema de trabajo, en el que el esfuerzo manual tenía un papel predominante, junto a las condiciones en las que tenía lugar el proceso productivo, $3^{8}$ llevaba a que el personal sufriera de enfermedades y se produjeran accidentes de trabajo, algo que en las magnitudes y en la dinámica de esas fábricas era cotidiano y se encontraba contemplado en la propia organización de los establecimientos, con la sección de enfermería y policlínica.

Por otro lado, existía en el propio diseño productivo de la fábrica una división sexual del trabajo, donde las tareas que requerían de cierta especialización, destreza en el uso de herramientas y esfuerzo físico, eran desempeñadas por hombres y tenían remuneraciones más elevadas. 39 Tal era el caso de las secciones de matanza, congelado y subproductos, así como también de la estiba, la carga y descarga que eran una decena por cada frigorífico. $4^{\circ} \mathrm{En}$ la sección conserva, donde se concentraba la mayor cantidad de mujeres -un 33\% según Camou-, el trabajo era más mecanizado y menos calificado, era un trabajo rutinario que no sólo se pagaba menos, sino que socialmente era menos considerado. ${ }^{41}$

\section{Los sindicatos friyeros}

Una importante expresión del sindicalismo cerrense lo constituían los sindicatos friyeros y la Federación que los nucleaba, la FOICA-A, fundada el 7 de enero de 1942 por el sindicato obrero del frigorífico Swift y el Sindicato obrero del Frigorífico Artigas. ${ }^{42}$ Esta organización federada fue además considerada como una de las más relevantes del movimiento sindical del país en las décadas del cuarenta y cincuenta. 43

\footnotetext{
37 De un conjunto limitado de fuentes relevadas en el repositorio documental existente en las instalaciones del Frigorífico Anglo en Fray Bentos, Departamento de Río Negro, Uruguay, se observan las tendencias mencionadas en las fichas del personal de los frigoríficos Swift y Armour.

38 Por mencionar algunos ejemplos, en diversas secciones, producto de la dinámica productiva con agua y vapor, los pisos se encontraban mojados. Algo similar sucedía en las playas de faenas donde la sangre y los desechos impregnaban los pisos. También en los depósitos el apilado manual de los cajones generaba riesgos para los trabajadores.

39 Camou 26.

40 Declaración de la FOICA, publicada en el periódico El Bien Público del 7 de junio de 1956, en Bonetti 106.

41 Camou 26.

42 Libro de actas de la Federación Obrera de la Industria de la Carne y afines autónoma, № $11942-$ 1946, folio 4 .

43 Hugo Cores, Aporte a la Historia del movimiento obrero uruguayo, tomo I, La lucha de los gremios solidarios (1947-1952), (Montevideo: Ediciones Banda Oriental, 1989).
} 
Entre muchos otros episodios, la Federación Autónoma de la Carne había sido protagonista del enorme movimiento huelguístico de los 'gremios solidarios' en 1951, que luego en 1952 enfrentó las medidas prontas de seguridad. En esa ocasión la FOICAA llegó a mantener durante unos días las medidas en solitario siendo la última en suspender dicha acción.

Los sindicatos frigoríficos cerrenses se organizaban a partir de los espacios de las fábricas, esto es, a partir de sus secciones. Cada sector productivo del frigorífico tenía sus delegados, que eran elegidos en sus respectivas asambleas y constituían además el vínculo directo entre los trabajadores y la comisión directiva del sindicato, electa mediante voto secreto por el conjunto de los afiliados. También las asambleas de secciones elegían delegados para participar en los órganos de la Federación (Congreso Nacional de Delegados y el Consejo Federal) confeccionando una lista de tres titulares por filial, que era refrendada por el sindicato en asamblea general y presentada a la FOICA-A. De este modo, el espacio de la fábrica se encontraba muy presente en la concepción política sindical de la Federación y sus sindicatos. La práctica sindical no podía estar separada del espacio físico del frigorífico, y el militante y dirigente sindical debía trabajar como cualquier otro trabajador, por ello se rechazaba la figura del militante 'rentado'. No se concebía al sindicato ni a sus directivos alejados de la vida cotidiana del frigorífico. Esta premisa orientaba la dinámica del conjunto de la organización, incluso de las reuniones sindicales. Por ejemplo, las instancias del Consejo Federal tenían pautadas de antemano una hora de finalización contemplando el necesario descanso de quienes ingresaban al frigorífico en los primeros turnos.

Pero esta forma de organización también reproducía la propia división sexual del trabajo de la fábrica, con una menor participación de las mujeres en la representación y responsabilidad sindical. En general, la participación de la mujer en el sindicato tenía lugar en el espacio de trabajo, como delegadas de sección (conserva, desosado, tripería, etc.), o participando en las asambleas de su área o en las generales. Fuera de la fábrica su presencia aumentaba en momentos de movilización y conflicto, esto es de paralización del trabajo. De hecho, en los organismos directivos cotidianos que funcionaban en los locales sindicales (tanto de los sindicatos friyeros como de la Federación Autónoma), casi que no figuraban mujeres. Incluso en los ámbitos más amplios de resolución de la FOICA-A (como el Consejo Federal que nucleaba en 
ocasiones cerca de 100 personas), era abrumadora la mayoría masculina. 44 Esta subordinación de las obreras en la organización sindical se explica por diferentes problemas que no es posible desarrollar en el presente trabajo, pero que es importante mencionarlo como una realidad de estas organizaciones obreras.

Políticamente la FOICA se ubicaba como "autónoma" y no era afín a ninguno de los reagrupamientos sindicales que existían hacia fines de los años cincuenta, aunque en diversas ocasiones, y en especial desde las huelgas de 1955-56, habían propiciado instancias de deliberación y coordinación sindical con las distintas centrales. ${ }^{45} \mathrm{Si}$ bien es difícil aún caracterizar y precisar la concepción política del sindicalismo autónomoe incluso del complejo arco sindical de los años cincuenta-, sí podemos señalar que se desarrolló en oposición al sindicalismo de orientación comunista. Ya en las actas de fundación de la FOICA-A se expresaban las tensiones con los militantes comunistas, ${ }^{46}$ que se harán más profundas luego de la huelga de 1943,47 y de la conformación por parte de estos de otra organización, la Federación Obrera de la Carne del Uruguay afiliada a la UGT, que con poca incidencia existió hasta 1955, año en que fue disuelta.48 El autonomismo de los sindicatos friyeros se asentaba también en una larga tradición de independencia de clase respecto al Estado y a todos los partidos políticos, combinando una acción de amplia negociación (con el gobierno y los parlamentarios), con la acción directa (movilización y huelga). Así como también la práctica solidaria con todos los sindicatos en lucha, incluyendo el movimiento estudiantil.49

\footnotetext{
44 En las actas relevadas del Consejo Federal de la FOICA en el período estudiado aparece ocasionalmente una delegada de la Unión Obrera Swift, como único caso de participación femenina en dicho ámbito.

45 Universindo Rodríguez, Silvia Visconti, Jorge Chagas y Gustavo Trullen, El sindicalismo Uruguayo a 40 años del congreso de unificación, (Montevideo: Santillana, 2006).

46 Según el libro de actas $N^{\circ} 1$ 1942-1946, en el folio 1 del acta correspondiente al 7 de enero de 1942, se acusa a militantes comunistas de traición al gremio y de hacer política partidaria, impidiendo sean considerados afiliados a la nueva organización.

47 En enero de 1943 se produjo el despido de diez trabajadores acusados de sabotaje a un buque inglés que transportaba un cargamento para los aliados, lo que motivó como respuesta una huelga de 5 días, que fue cuestionada por los comunistas. Ver Rodolfo Porrini, "Experiencia e identidad de la nueva clase obrera uruguaya: la huelga frigorífica (montevideana) de enero de 1943", Historia UNISINOS 6, (2002), 63-96.

48 Gerardo Leibner, Camaradas y compañeros, una historia política y social de los comunistas en Uruguay, (Montevideo: Trilce, 2011), 253.

49 Así lo grafica su participación protagónica en las huelgas de los gremios solidarios en 1951 y 1952, los paros solidarios con gremios en conflicto durante todo el período, y las diversas convocatorias a coordinaciones entre gremios de trabajadores y estudiantiles, así como a instancias de discusión de unidad sindical (1956).
} 


\section{La política del gobierno frente al cierre}

A fines de 1957, el grupo International Packers anunció en New York el cierre de sus filiales en Montevideo, y el 20 de diciembre de ese año se hizo efectivo el cierre de los frigoríficos Swift y Artigas. El testimonio del obrero y dirigente de la Unión Obrera Swift, Enrique Toja, es significativo para acercarnos al impacto que esta medida tuvo sobre la barriada cerrense: el cierre "trajo pánico en el Cerro, nadie creía que los frigoríficos se fueran, todos pensaban que era una maniobra de los 'gringos', que era una maniobra más a los efectos de buscar prebendas. Inclusive en la Federación de la Carne, nadie creía que la cosa fuera así”.50

Al cerrar, esas empresas adeudaban aportes a la Caja de Compensaciones por Desocupación por un monto que según la prensa rondaba los 2 millones de pesos, además de licencias del personal correspondientes a 1957 e indemnizaciones por despido. Además, continuaba la investigación parlamentaria iniciada en 1956 a raíz del conflicto que había tenido lugar ese año entre los sindicatos y las empresas. La comisión encargada del estudio buscaba establecer los costos y las ganancias de los frigoríficos extranjeros y había presentado su primer informe -que seguía sin ser tratado en las Cámaras- que ya denunciaba alteraciones de los balances contables y fraudes varios al Estado.

Al problema de la pérdida del empleo por el cierre de las fábricas y la incertidumbre que esto generaba en las familias obreras, se le sumó la resolución del gobierno que desvinculó a los obreros del Swift y Artigas de la Caja de Compensaciones por Desocupación. Las autoridades aducían que eran las empresas quienes se encontraban afiliadas a dicha Caja y por lo tanto correspondía, producto de la clausura de los establecimientos, desvincular a los obreros y obreras del Swift y del Artigas de dicho organismo. Señalaban además como fundamentación, que si esto no se hacía efectivo el organismo corría riesgo de desfinanciamiento.

Esta medida generó una situación de completo desamparo para más de cinco mil hogares cerrenses, pues los trabajadores no percibieron ningún tipo de

50 Alba Medina, “La sindicalización en la carne”, Revista Estudios111(1994), 106. 
remuneración ni subsidio durante todo el verano, con excepción de las asignaciones familiares.

Estos primeros meses fueron realmente críticos para gran parte del Cerro. Las familias obreras pasaron por todo tipo de privaciones. Según relata el diario comunista El Popular, decenas de ellas fueron desalojadas de sus casas por no poder hacer frente al pago de los alquileres, la alimentación se vio resentida -pues no contaban con la carne que era parte fundamental de la dieta cotidiana ${ }^{51} \mathrm{y}$, además, tampoco disponían de sus remuneraciones. Según algunos testimonios que hemos recabado, la mayoría vivía del fiado de los almacenes del barrio, algunos subsistían gracias a los ingresos de algún miembro del núcleo familiar que trabajaba fuera de las fábricas o a la ayuda de otros integrantes de la familia. Algunos lograron conseguir changas o trabajos circunstanciales, muchos hogares sufrieron el hambre y la mala alimentación.

La situación que se vivía en la Villa del Cerro repercutía a través de los periódicos en todo el país. Por ejemplo, el semanario socialista $\mathrm{El} \mathrm{Sol-entre} \mathrm{otros-tituló} \mathrm{en} \mathrm{su}$ portada del 28 de marzo, "El Cerro tiene hambre", mientras que el diario comunista $E l$ Popular del 10 de marzo habló de "Indignación en los hogares de los obreros de la carne". ${ }^{2}$

Luego de meses de espera, la paciencia de los obreros llegó a su fin y el 8 de abril la Federación Autónoma de la Carne comenzó una huelga general que paralizó la Industria a nivel nacional, en reclamo del pago de las remuneraciones adeudadas, por la re-vinculación de los trabajadores del Swift y del Artigas a la Caja de Compensaciones por Desocupación y, por la inmediata apertura de las fábricas cerradas. La huelga duró 14 días y cumplió parcialmente con sus objetivos. Por un lado, logró modificar la resolución del gobierno, que aprobó la ley 12495 mediante la cual se capitalizó con 2 millones de pesos a la Caja de Compensaciones, para efectivizar los pagos adeudados por tres meses a los obreros.53 Por otro lado, consiguió también la

51 Incluido en lo que se denominaba beneficios sociales, los trabajadores de los frigoríficos recibían 2 quilos de carne por día (de lunes a sábado), que retiraban semanalmente realizando un pago simbólico de unos centavos.

52 Diario, El Popular, Montevideo, 10 de marzo de 1958, portada.

53 Pablo S. Landos, "La expropiación de los frigoríficos imperialistas y su integración al patrimonio nacional, una cronología de los principales hechos”, Revista Estudios9(1958), 26-30. 
aprobación de las leyes 12499 y 12498, por las cuales se re-vinculó a los obreros y a los empleados a la Caja de Compensaciones y se estableció a texto expreso, el derecho al cobro de la indemnización por despido.54Por último, logró que el Consejo Nacional de Gobierno emitiera un decreto de intervención del Frigorífico Swift para que su apertura se efectuara bajo jurisdicción del Consejo Nacional de Subsistencias, el Frigorífico Nacional y una comisión especial.55

La paralización del trabajo durante dos semanas en toda la industria suscitó variados detractores. Sectores capitalistas afectados y de las derechas reclamaron poner fin a la paralización 'salvaje' a través de mecanismos de reglamentación sindical. Periódicos como el católico El Bien Público y el quincista pro-gubernamental Acción se expresaban en este sentido. Incluso la comisión que asesoraba al Poder Ejecutivo en materia de carnes, recomendó en un informe la reglamentación del derecho de huelga. $.5^{6}$

Pero también la medida de lucha de los trabajadores recogió apoyos variados, que tuvieron expresión en el paro general solidario del 24 de abril de 1958 que incluyó al conjunto del movimiento sindical.

Si bien la huelga de abril permitió a las familias cerrenses salir transitoriamente de la asfixia financiera a la que estuvieron sometidas, no logró una resolución efectiva de reapertura inmediata de las fábricas, por lo cual se vivieron "nuevos meses de angustia". 57

Para gran parte de la población cerrense, que estaba paralizada, "pasaban meses que parecían años, con el Swift y el Artigas cerrados". ${ }^{8}$ La FOICA-A discutió y propuso un proyecto de expropiación y gestión cooperativa por parte de los trabajadores que

\section{Landos 26-30.}

55 El 16 de setiembre de 1958 se promulgó la ley 12523 por la cual se proveía al Consejo Nacional de Subsistencias y Contralor de Precios de $\$ 5.613 .248$ para atender los gastos de reapertura, funcionamiento, y adquisición de materia prima, del establecimiento frigorífico intervenido por decreto del Poder Ejecutivo del 25 de abril de 1958 (Swift). Landos 26-30.

56 Diario El Popular, 4 de marzo de 1958, p 8.

57 Ídem.

58 Laureano Riera, “EFCSA y el drama de una experiencia”, Revista EFCSA 7 (1960), 4. 
fue aprobado por el Congreso Nacional de Delegados (CND) como base de negociación con el gobierno para la reapertura de las fábricas.

Finalmente, según lo que diversas fuentes señalan,59 luego de varios meses de negociaciones y de un trabajo conjunto entre dirigentes de la FOICA- A y del Dr. De Ferrari (presidente de la Caja de Compensaciones por Desocupación de la Industria Frigorífica durante el período, vinculado a la lista 14 del Partido Colorado), se transformó y ajustó al derecho liberal el proyecto aprobado por el CND de expropiación y gestión cooperativa de los trabajadores, creándose una empresa privada, de giro Sociedad Anónima, propiedad de todos los obreros y empleados que figuraban en los registros de personal al 1 de diciembre de 1957.

Esta propuesta fue la que finalmente se aprobó por parte del parlamento el 16 de octubre de 1958 (a cuarenta días de las elecciones nacionales) con la ley $12542 .{ }^{60} \mathrm{Se}$ creó así Establecimientos Frigoríficos del Cerro. S. A (EFCSA).

\title{
La nueva empresa
}

Establecimientos Frigoríficos del Cerro. S.A nació el 30 de octubre de 1958, y se puso en funcionamiento rápidamente. Si bien la empresa era propiedad de sus obreros y empleados, asemejándose así a una experiencia cooperativa, la dirección de la misma

\begin{abstract}
59 Entre otras fuentes, Mechoso señala que algunos dirigentes de filiación batllistas de la Federación consultaron la viabilidad del proyecto aprobado con el Dr. Francisco De Ferrari, un reconocido jurista que le dio el visto bueno pero introdujo modificaciones transformándolo en una Sociedad Anónimas en la que obreros y empleados eran los principales accionistas. En entrevista realizada por Rodolfo Porrini, 5 de julio de 2014, inédita, desgrabada en el marco del proyecto CSIC I+D "El Cerro en los años sesenta (1957-1973), ¿barrio de trabajadores o comunidad obrera?.
\end{abstract}

6o La ley 12.542 estableció las bases por las cuales las empresas extranjeras transfirieron sus establecimientos industriales y demás bienes inmuebles, maquinarias y derechos a una sociedad anónima integrada por los obreros y empleados de los frigoríficos Swift y Artigas. La ley exoneró de impuestos la transacción de compra venta, además de permitir a las compañías extranjeras realizar la venta sin estar al día con sus obligaciones con el Estado (Caja de Jubilaciones y Pensiones de la Industria y Comercio, Caja de Asignaciones Familiares, Caja de Compensaciones por Desocupación de la Industria Frigorífica, impuesto sustitutivo de las herencias, Contribución Inmobiliaria, patentes y demás). Por otra parte, las deudas a las tres Cajas antes mencionadas se liquidaron a favor de sus obreros y empleados, y la sociedad que estos debieron constituir las abonaría en un plazo de veinte años con un interés del $5 \%$ anual. La ley estableció que las acciones de la sociedad que se constituyera, debían ser entregadas a los obreros y empleados, en pago de sus créditos por concepto de licencias e indemnizaciones por despido. Pero estas acciones serían nominativas y no podrían ser negociadas durante el término de 10 años. También por 10 años la nueva empresa sólo podía permitir la suscripción de acciones a nombre de personas que estuvieran vinculadas a la misma en calidad de obreros o empleados. La ley contemplaba que los trabajadores de EFCSA no perdían los beneficios antes adquiridos en la ley 10562 del 12 de diciembre de 1944. 
integraba a personalidades de la política local, que muchas veces se habían manifestado afines a intereses divergentes al de los gremios friyeros. El primer directorio de EFCSA se compuso de seis miembros y fue presidido por el abogado y reconocido líder del Partido Colorado, Cesar Charlone, un hombre clave durante la dictadura de Terra (1933-1938) como ministro de Hacienda y luego como vicepresidente bajo el gobierno de Alfredo Baldomir (1938-1942). Fue secundado por el Dr. Francisco De Ferrari. Los cuatro integrantes restantes del directorio fueron Julio Arocena Folle, hombre vinculado al sector ganadero y secretario de la Asociación Rural en 1949, Abel J. Ferrando empleado durante 30 años y Gerente General del Frigorífico Artigas, ${ }^{61}$ más los dirigentes sindicales Carlos Buchelli, presidente de la Federación Autónoma de la Carne al 5 de marzo de 1958 y Edelfo Yañez, presidente de la Asociación de Supervisores y Empleados de la Industria Frigorífica (ASEIF). ${ }^{62}$

Ya desde su conformación, en las páginas del periódico anarquista Lucha Libertaria ${ }^{63}$ se consideraba que los representantes obreros eran minoría en el Directorio, marcando así una disociación de intereses sociales y políticos en la conducción de EFCSA.

La empresa comenzó a trabajar de forma inmediata y hacia diciembre de ese año, ya había exportado importantes cantidades de productos, incorporando al trabajo a 1700 obreros y empleados de ambas fábricas. ${ }^{64}$ Para informar sobre su marcha, la vida de la fábrica y la dinámica y problemas de la industria de la carne, a partir de enero de 1959 el directorio comenzó a editar una revista quincenal llamado EFCSA, cuyo lema era Hace bien al país y merece bien del país.

La apertura de EFCSA también puso en discusión entre los trabajadores, los problemas derivados de las normas que regulaban al mercado y faena de la carne, sobre todo las que referían al monopolio del abasto que detentaba el Frigorífico Nacional.65

61 Revista EFCSA1, (1959).

62 Diario El Popular, Montevideo, 5 de marzo de 1958, p 12.

63 Periódico Lucha Libertaria, Montevideo, Diciembre, 1958, p. 5.

64 Riera 5.

65 Dicho monopolio ya había sido cuestionado en el pasado por diversos actores del arco político, frente a las crisis de escasez, y por las propias empresas extranjeras que añoraban participar en el mercado interno, ahora se colocaba nuevamente en el escenario nacional a impulso de los cambios políticos y económicos que se anunciaban con el triunfo del Partido Nacional en las elecciones de fines de noviembre de 1958 . 
Estas normas proteccionistas establecían que los Establecimientos Frigoríficos del Cerro S.A debían orientar su producción hacia la exportación. Al igual que en el pasado lo habían hecho las empresas norteamericanas, la directiva de EFCSA comenzó a cuestionar esta política, argumentando que ya no actuaban en el mercado los capitales norteamericanos y, por lo tanto, era necesario liberalizar el abasto del mercado interno. Este tema fue un punto de divergencia política entre los gremios obreros del Cerro, no sólo con la organización sindical del Frigorífico Nacional sino también al interior de la FOICA-A, pues la Federación hasta ese momento siempre había sido una férrea defensora de esta norma. De hecho, el nuevo gobierno del Partido Nacional implementó en 1959 el régimen de abasto libre, eliminando el monopolio del frigorífico Nacional, que sólo quedó con el monopolio de faena. ${ }^{66}$

Si bien la creación de EFCSA tenía como fin reactivar las plantas frigoríficas cerradas y de ese modo garantizar la fuente de trabajo de los obreros cerrenses, la primera medida que tomó el Directorio de la nueva empresa fue poner en funcionamiento solamente la planta Artigas, convocando a trabajar a una parte del personal que comprendían ambas empresas.

Se cristalizó así una primera diferenciación que luego resultó en una división de los obreros, entre aquellos que habían sido convocados a trabajar y entre los que aún permanecían desocupados. El periódico Lucha Libertaria lo manifestaba de este modo: esa situación "generó descontento entre los trabajadores que no habían sido llamados a trabajar"67, mientras que "los que lo han empezado a hacer, parecerían conformarse sólo con ello”, ${ }^{68}$ dejando entrever cierta falta de interés de parte de quienes eran convocados al trabajo por el resto de los trabajadores y por el rumbo futuro de la empresa.

El directorio de EFCSA adujo que no era posible la reapertura de la planta del Swift, porque según un estudio de técnicos e ingenieros era necesario realizar en la fábrica algunas reparaciones y un reacondicionamiento general, que implicaban un alto costo que la empresa no podía cubrir pues -según afirmaba- había tenido que gestionar empréstitos multimillonarios para poner en funcionamiento la planta

66 Barrios Pintos y Reyes Abadie 71.

67 Periódico Lucha Libertaria, Montevideo, Diciembre 1958, p. 5.

68 Ídem. 
Artigas. Los directivos también señalaron problemas de rentabilidad en el funcionamiento de la planta Swift, en relación de su gran capacidad con el reducido ganado disponible. Sin embargo, algunos dirigentes de la FOICA-A, aportaron otra explicación a tal decisión. Decía Jorge García que "así la dirección de EFCSA dejaba de lado a una serie de dirigentes que no estaban de acuerdo con la formación de EFCSA en forma de Sociedad Anónima, como se formó al fin.” 69

Como vemos, esta decisión de la apertura de la planta Artigas, aparece a los ojos de los sindicatos débilmente justificada y comienzan a evidenciarse divergencias respecto a la administración de la empresa.

Si bien la propiedad de las plantas estaba en manos de los obreros y empleados de forma individual a través de acciones, EFCSA ingresó al mercado como empresa privada y la lógica que predominó en su dirección fue la de lograr un buen rendimiento para que el establecimiento continuara funcionando. La idea de una "gestión obrera o cooperativa obrera" que en un principio primó entre los trabajadores y en el ámbito gremial de la Federación Autónoma de la Carne, comenzó a verse cuestionada a medida que avanzaba el plan de trabajo resuelto por el Directorio, en el cual las instalaciones del Swift eran utilizadas para algunos trabajos, pero no se ponía en funcionamiento la faena. ${ }^{70}$

\section{El conflicto}

Durante el primer año de funcionamiento de la empresa, comenzó un debate en los organismos de la gremial obrera sobre la política de EFCSA y sobre el carácter que adquiría la medida de paro o huelga. ${ }^{71} \mathrm{La}$ idea predominante en muchos gremialistas y pobladores del Cerro señalaba que EFCSA era una verdadera cooperativa obrera y que el extenso y desesperado período de desocupación que vivieron los obreros del Cerro, durante el cierre de ambas plantas, generó un efecto de defensa acérrima de EFCSA,

69 Jorge García, Memorias de un friyero, 1917-1969, (Montevideo: CIPFE, 1984), 12.

70 Según la revista EFCSA 1 (Enero 1959), el plan del Directorio establecía la instalación en la planta Montevideo de una gran industria de elaboración de cerdas, así como también el impulso a la sección jabonería y a la sección tonelería, y especialmente a la venta de frío. También informaba que estaba realizando estudios para la preparación de raciones balanceadas y la elaboración de fertilizantes.

71 Libro de Actas del Congreso de Delegados de la FOICA, 1958. 
compartido por muchos dirigentes sindicales y gran parte de sus trabajadores y trabajadoras.

De algún modo, las diferencias entre los gremios del Artigas y del Swift se expresaron desde el inicio de la discusión en torno a la reapertura de las fábricas. La Unión Obrera Swift se opuso al proyecto cooperativo, así como también a la creación de la Sociedad Anónima, pues consideraba que las plantas tenían que pasar a manos del Estado. Según Laureano Riera, en el seno de la FOICA-A, los delegados del Swift votaron contra la transferencia, que fue respaldada por mayoría. ${ }^{2}$ Por su parte, el sindicato Obrero del Frigorífico Artigas y la filial correspondiente de ASEIF, defendieron desde el inicio la experiencia de EFCSA y más aún luego de su puesta en funcionamiento, pues estableció la reapertura del frigorífico garantizando empleo primero a los obreros de dicha planta. Ambos sindicatos y la propia dirección de la FOICA-A, se encontraron en la primera etapa más integrados a la gestión de EFCSA, sobre todo a través de algunos de sus dirigentes y de los directores obreros. Los trabajadores y los gremios del Frigorífico Artigas consideraban a EFCSA como su empresa, una cooperativa realmente obrera. Por este motivo, aceptaban como un sacrificio necesario los aumentos de la productividad, de la jornada laboral o incluso la flexibilidad en la recepción de los beneficios sociales, así como también consideraban innecesarias las medidas de paros y huelgas, pues entendían que perjudicaban a ellos mismos. Se valoró, sobre todo, mantener en funcionamiento la fábrica (su rentabilidad), para garantizar la fuente de trabajo.

Juan Carlos Mechoso fundador de la Federación Anarquista del Uruguay (FAU) y obrero del frigorífico Alianza en su juventud, quien vivió durante nuestro período en La Teja y posteriormente en el Cerro, realiza la siguiente distinción:

los gremios del Swift y del Artigas eran muy distintos, los trabajadores del Swift (...) tenían otra tradición, muy combativo el Swift, mientras que los del Artigas (...) eran trabajadores, que en general, que iban, estaban afiliados, disciplinariamente iban a la huelga. Pero eran de muy baja combatividad tradicionalmente.73

72 Riera 5 .

73 En entrevista a Juan Carlos Mechoso, realizada por Rodolfo Porrini en Montevideo el 5 de julio de 2014. 
Otro de los primeros problemas que enfrentó a las dos organizaciones tuvo que ver con el incumplimiento por parte de EFCSA, a causa de falta de stock ganadero, de uno de los beneficios sociales (entrega de los dos kilos de carne diarios establecidos por Consejo de Salario y por la propia ley de creación de EFCSA). Este hecho generó importantes tensiones en la interna de la Federación, que en julio de 1960 discutió el tema en el Congreso Nacional de Delegados (CND). El punto fue planteado en dicho órgano por la Unión Obrera Swift (UOS), en divergencia con el Sindicato Obrero del Frigorífico Artigas, quién se retiró de la sesión, mencionando que había realizado un acuerdo con la UOS para discutir el tema en conjunto, antes de presentarlo en ese ámbito. ${ }^{74} \mathrm{El} \mathrm{CND}$ continuó funcionando y resolvió mandatar a los 'directores obreros' de EFCSA (presentes en la reunión) a proponer en el directorio el inmediato cumplimiento de los beneficios sociales por parte de la empresa. En caso de que la resolución del organismo fuese negativa, el CND facultó a la Comisión Administrativa de la FOICA- A a aplicar las medidas de lucha que esta considerara conveniente'.75

Las tensiones se transformaron en abierto conflicto cuando el directorio de EFCSA resolvió enviar "a la orden" a todo el personal del ex Swift, medida que la UOS entendió como una pretensión definitiva de clausura del frigorífico, por lo que resolvió el 26 de julio la ocupación de la planta Montevideo y la separación de la Sociedad Anónima. ${ }^{76}$

Así informaba sobre el conflicto y la ocupación, el delegado de la UOS ante el Congreso Nacional de Delegados: "creemos que la gestión de EFCSA ha fracasado y por ello como la Federación ha sido la creadora de este engendro de frigoríficos del Cerro, por eso decidimos que la Federación tome cartas en el asunto y lleve adelante nuestra aspiración de separación”. 77 Por su parte, el director obrero Edelfo Yañez contestó que no existía ninguna resolución de cierre y que lo que se planteaba era el envío "a la orden" del personal del Swift, porque si no tendrían que cerrar ambas plantas..$^{78}$ Frente a lo cual, el delegado de la UOS Bentos Pereira, manifestó que la situación era que habían "muchos compañeros que han trabajado solamente unos meses, otros en

74 Acta Congreso Nacional de Delegados, 13 de julio de 1960.

75 Acta Congreso Nacional de Delegados, 13 de julio 1960.

76 Acta Congreso Nacional de Delegados, 30 de julio de 1960, folio118.

77 Acta Congreso Nacional de Delegados, 30 de julio 1960, folios 118-120.

78 Acta Congreso Nacional de Delegados, 30 de julio 1960, folios 118-120. 
changas en otros frigoríficos, y otros hace más de dos años que no tienen trabajo" ${ }^{79 E n}$ su intervención manifestaba aspectos de la crisis social que vivía el país, producto del aumento de la desocupación y del costo de vida.

Mientras que algunos delegados intentaron apaciguar los ánimos y propusieron resoluciones que tuvieran en consideración ambas realidades, otros se volcaron decididamente en apoyo al reclamo de la UOS. El director que representaba a los obreros en el directorio del Frigorífico Nacional, Oscar Carrera, histórico dirigente de la gremial, propuso resolver el problema con la rotación equitativa en el trabajo, con el nombramiento de una comisión de investigación sobre los costos y ganancias, y el rechazo al cierre del frigorífico Swift. ${ }^{80}$ Mientras que José A. Almeida, delegado del Sindicato de Carga y Descarga, manifestó que "debemos encontrar soluciones que no pongan en peligro la conquista obtenida por la Federación al consolidar la adquisición de las plantas por parte de los obreros". ${ }^{81}$

Finalmente, el Congreso resolvió a favor de la UOS, facultando a la Comisión Administrativa para que gestionara por las vías que correspondieran la separación jurídica de la Sociedad Anónima. ${ }^{82}$ A partir de esta sesión el Sindicato Obrero del Frigorífico Artigas y su sección de ASEIF, los directores obreros de EFCSA y el delegado por la FOICA-A a la Junta Nacional de Carnes Laureano Riera, dejaron de asistir al Congreso Nacional de Delegados.

Se estableció un acuerdo por el cual el directorio de EFCSA convocó una asamblea de accionistas -que tuvo lugar el 31 de agosto de 1960- para resolver la solicitud de separación de la UOS.

Las tensiones del conflicto se hicieron públicas a partir de artículos firmados por el Directorio de EFCSA en su boletín informativo y por una nota de Laureano Riera en el Semanario Marcha,en los que se atacaba a la Federación Autónoma de la Carne y se denunciaba que la organización estaba siendo copada por militantes políticos del Partido Comunista.

79 Acta Congreso Nacional de Delegados, 30 de julio de 1960, folio 121. 80 Acta Congreso Nacional de Delegados, 30 de julio de 1960, folio 122. 81 Acta Congreso Nacional de Delegados, 30 de julio de 1960, folio 122. 82 Acta Congreso Nacional de Delegados, 30 de julio de 1960, folio 122. 
El 26 de agosto el CND expulsó a Laureano Riera de la Federación y lo retiró como delegado de la Junta Nacional de Carnes. El 23 de setiembre el CND expulsó también a los directores obreros de EFCSA y resolvió realizar un mitín en el local de la Federación, para hacer pública entre otras cuestiones esta resolución. Un mes después, en función del apoyo a la política del directorio de EFCSA y la no paralización de actividades en la jornada solidaria con la revolución cubana, el CND resolvió, a propuesta del presidente Artigas Sánchez, la

suspensión preventiva de la afiliación a la Federación Autónoma de los sindicatos Artigas y ASEIF, estableciendo por nota a estas filiales, la exigencia de llamar a asambleas generales dentro de un plazo de 20 días para que estas se pronuncien con claridad su adhesión sin condiciones a la central y su acatamiento por todas las decisiones que adopte el Congreso Nacional de Delegados, como establecen los estatutos. ${ }^{83}$

Luego de que la FOICA-A rechazara la resolución de la asamblea de accionistas de EFCSA sobre las condiciones para la separación de la planta Montevideo, el reclamo pasó a ser que se abriera la planta por dos años como medida experimental bajo la administración del Frigorífico Nacional. ${ }^{84}$

\section{La fractura de los gremios de la carne}

Los debates sobre el carácter de EFCSA, los problemas de la industria, la situación de los trabajadores y de los gremios, así como los caminos y las estrategias a seguir, aparecieron en programas de radio, en volantes ${ }^{85}$, comunicados de los gremios y de la Federación, en la prensa en general y sobre todo en la de las organizaciones de izquierda (comunista, socialista y anarquista, entre otras). También en la propia acción: movilizaciones, mítines y enfrentamientos que tienen lugar en el Cerro.

Se formulan, de forma pública, acusaciones cruzadas entre militantes y dirigentes 'históricos' de la FOICA-A ${ }^{86}$, muchos de los cuales habían estado en diversas

83 Acta Congreso Nacional de Delegados, 23 de setiembre de 1960.

84 Periódico Lucha Libertaria, Montevideo, Mayo de 1961, p 10.

85 Manifiesto de la FOICA- A, "Enfrentando la crítica confusionista, con Razón y la Verdad”, Agosto, 1960. En colección personal de Gustavo "Bucky” Delgado.

86 Desde las páginas del boletín informativo de EFCSA año 3, Número 15 y 16 correspondientes a Abril y Mayo de 1961, se publicaron extractos de los directores obreros de dicho establecimiento donde hacían referencia a que los dirigentes de la FOICA faltaban a la verdad, se publicaron además en el Semanario Marcha un serie de artículos del ex dirigente Laureano Riera dónde atacaba a la Federación de la Carne y denunciaba que la organización estaba siendo copada por militantes políticos del Partido Comunista. 
ocasiones en la primera línea de las batallas del gremio, como por ejemplo en la huelga de hambre de $1955 .{ }^{87} \mathrm{~A}$ veces incluso al interior de las familias o entre los vecinos cercanos se manifestaban las tensiones entre quienes defendían una u otra posición.

Los que estaban más relacionados a la experiencia de EFCSA y la defendían como una cooperativa obrera, denunciaban que detrás de las posiciones y "medidas intransigentes" de la Federación, se encontraban los comunistas, que al parecer comenzaban a tener mayor incidencia, luego de disolver a partir de 1955 la gremial que estaba bajo su predominio e integrar a sus militantes a la Autónoma. Este punto de vista también es esbozado por el periódico anarquista Lucha Libertaria, ${ }^{88}$ que bajo la redacción de Rubens Barcos planteaba cierta incidencia de militantes de los "partidos marxistas" en la FOICA-A, cuya estrategia consistía en hacer que EFCSA fracasara como experiencia cooperativa para solicitar su estatización. ${ }^{89}$

El quiebre definitivo en los gremios de la carne tiene lugar a comienzos de 1961, cuando luego de realizar una asamblea nacional con paralización de todas las filiales del país el 11, 12 y 13 de abril, la FOICA-A declara el 24 de ese mes la huelga general en toda la industria por la reapertura del ex Swift. Por primera vez desde la huelga de 1943 (que tanto marcó a los obreros y a la barriada cerrense), los gremios de la carne se

La FOICA por su parte respondió las acusaciones a partir de un Manifiesto que titulaba "enfrentando la Crítica confusionista con la Razón y la Verdad” donde presentaba a los trabajadores las reivindicaciones y defendía la actuación de los representantes de la Federación, y la separación del establecimiento Swift y su reapertura.

87 Por ejemplo, Antonio Fernández, quien asume como director en 1961 frente a la renuncia de uno de los directores obreros, fue secretario general del Sindicato Obrero del Frigorífico Artigas en los años 1943,1944, 1952, 1957 y 1958.En el año 1946 fue prosecretario, en 1956 fue vicepresidente de la FOICA y se plegó a la primera huelga de hambre en 1955, cuando la Federación era presidida por Raúl Moreira. En Revista EFCSA, “Un obrero más en el Directorio", año 3, №15, Montevideo, abril 1961, p 2.

88 Periódico, Lucha Libertaria, BARCOS, Rubens "División en el gremio de la Carne, están buscando destruir la Federación Autónoma," n 204, Julio de 1960, p 11.

89 En este sentido, Héctor Herrera, obrero del Frigorífico Nacional y entonces militante comunista afirma que "recién en el año 1959, 1960 cuando se gana el Nacional a la orientación del PCU, que fueron desplazados los anarquistas y los partidos tradicionales, se procede a la unificación del movimiento sindical. Ya contábamos con presencia del Partido en el Fray Bentos y en Casa Blanca que era el de Paysandú, y ahí se comenzó a dar la pelea por la unificación del movimiento sindical con la preponderancia del PCU hasta la dictadura y después inclusive”, Entrevista a Héctor Herrera, realizada por Lucia Siola, Montevideo 17 de abril 2018.

Por su parte Gerardo Leibner registra dos hechos que muestran la incidencia de los comunistas en el barrio y en el gremio de la carne: en 1958 el obrero P. Sánchez del Frigorífico Swift habló en una audición del PCU y figuró luego en las listas de dicho partido (lo que supone que no ocupaba ninguna representación gremial); en diciembre de 1961 en el marco de una huelga de la Federación, el PCU realizó una fiesta de fin de año en el Cerro, siendo "el primer evento público y masivo de esas características que los comunistas pudieron realizar desde aquel conflicto de 1943”. Leibner 273. 
dividen y algunos realizan la medida mientras que otros continúan trabajando. ${ }^{\circ}$ Los obreros de la planta Artigas cuestionan la decisión del CND y en una asamblea efectuada el 8 de abril de 1961 resuelven "no acompañar la huelga por tiempo indeterminado que tendría lugar a partir del 24 de abril, trabajando de forma normal". ${ }^{11}$ La huelga comienza a ser resistida también por los obreros del Frigorífico Nacional, ante las amenazas del gobierno de quiebre y cierre de la empresa si la medida se extendía, así como de la implementación de sanciones. También comienza a repercutir en el interior del sindicato la división que se había expresado en la Federación. En este marco, la Confederación Sindical del Uruguay (CSU) empieza a tener influencia dentro del gremio y genera una corriente de crítica a sus dirigentes, con una fuerte prédica anticomunista.

El 4 de mayo de 1961 efectivamente se produce una división del Sindicato de Obreros y Obreras del Frigorífico Nacional y se crea la Unión Obrera Libre del Frigorífico Nacional (presidida por Walter Burghi, quién fue uno de los oradores del acto del $1^{\circ}$ de mayo organizado por la CSU en Belvedere). La división también se generó en el gremio de empleados, donde se produce la fractura de ASEIF y se crea la Asociación de Funcionarios del Frigorífico Nacional.

La derrota de la huelga y de la extensa ocupación de más de once meses realizada por la Unión Obrera Swift, abrió paso al definitivo cierre de una de las plantas industrializadoras de carne más importantes que tuvo el país y el Cerro. Según Jorge García se inició así el proceso de "descentralización" de la industria frigorífica hacia el interior del país, pues fue EFCSA quien desmanteló la planta Swift, sacando su maquinaría para llevarla hacia Durazno, Cerrillos y venderla a otros frigoríficos. ${ }^{22}$

\section{A modo de cierre}

El recorrido histórico que hemos presentado en el presente trabajo, que debe ser profundizado y mejor analizado en futuras elaboraciones, pretendió describir y aportar sobre algunos sucesos que pautaron la crisis, las tensiones y las

\footnotetext{
90 Si bien en 1948 se produce un alejamiento provisorio del Sindicato de Obreros del Frigorífico Nacional de la FOICA-A, todos los sindicatos friyeros participan de las huelgas de los gremios solidarios en 1951 y 1952.

91 Revista EFCSA1, (1959).

92 García 13.
} 
transformaciones que vivieron hacia fines de la década de los cincuenta los sindicatos cerrenses de la industria frigorífica.

El artículo da cuenta de cómo el cierre y posterior reapertura de una sola de las fábricas repercutió en la dinámica de vida de los trabajadores, -que vivieron varios meses de desocupación-y en la de sus organizaciones sindicales que se vieron atravesadas de tensiones y divisiones. Muestra también cómo la crisis industrial y económica más general actuó como telón de fondo en la modificación de la acción y de la conciencia de los trabajadores y sus organizaciones.

Por último, muestra el comienzo de un proceso de transformación de la industria frigorífica, que se extenderá por toda la década y que estará acompañado por múltiples resistencias y una fuerte lucha de clases. Dicho proceso tendrá como base no sólo la descentralización de los establecimientos hacia el interior del país, sino más específicamente, la reestructuración de las fábricas y el paulatino abandono de aquellos grandes establecimientos, las llamadas "catedrales del cornedbeef".

\section{Fuentes}

\section{Entrevistas}

Eva Luna, obrera de la planta Artigas - EFCSA, realizada por Lucía Siola y Alesandra Martínez, Montevideo 20 de setiembre de 2018, inédita, realizada en el marco del proyecto CSIC I+D "El Cerro en los años sesenta (1957- 1973), ¿barrio de trabajadores o comunidad obrera?

Héctor Herrera, obrero del frigorífico Nacional, realizada por Lucía Siola, Montevideo 17 de abril de 2018, inédita, realizada en el marco del proyecto CSIC I+D " $E l$ Cerro en los años sesenta (1957-1973), ¿barrio de trabajadores o comunidad obrera?

Juan Carlos Mechoso, fundador de la Federación Anarquista del Uruguay, obrero del frigorífico Alianza, canillita, y obrero gráfico, entrevista realizada por Rodolfo Porrini en Montevideo el 5 de julio de 2014, desgrabada en el marco del proyecto CSIC I+D "El Cerro en los años sesenta (1957-1973), ¿barrio de trabajadores o comunidad obrera?

María Julia Alcoba, obrera textil, entrevista realizada por Lucía Siola y Agustín Juncal, 20 de diciembre de 2017, inédita, realizada en el marco del proyecto CSIC I+D "El Cerro en los años sesenta (1957-1973), ¿barrio de trabajadores o comunidad obrera?

Sergio Iglesias, Nicolás Trujillo y Alberto Garategui, obreros de la industria frigorífica, militantes de la (Asociación de Jubilados y Pensionistas de la Industria de la Carne y Afines (AJUPEN- FOICA), realizada por Lucia Siola y Rodolfo Porrini, 
Montevideo 16 de abril de 2018, inédita, realizada en el marco del proyecto CSIC I+D "El Cerro en los años sesenta (1957-1973), ¿barrio de trabajadores o comunidad obrera?

\section{Prensa periódica}

Diario El Popular, Marzo, Abril, Noviembrede1957.

Mensuario Lucha Libertaria 1958, 1959, 1960, 1961.

Semanario El Sol, 1957,1958.

Diario ElBien Público, $1958 \mathrm{y} 1962$

\section{Revistas}

Revista EFCSA, Año 1,2,3 y4(Enero 1959 a Agosto1962.)

Revista Estudios, Año 3, № 9, 1958, Año 4, No 11,1959, yAño38, ํo111,1994.

\section{Fuentes y documentos sindicales}

Estatutos de la Federación de Obreros de la Industria de la Carne y Afines, Montevideo,1958.

García, Jorge, Memorias de un friyero, 1917-1969, Montevideo: CIPFE, 1984.

Informe de la secretaria general de la Confederación Sindical del Uruguaya su congresodel10al13deagostode1961realizadoenMontevideo, impreso el 2ode julio de 1961 en la imprenta Goes.

Libro de Actas del Congreso Nacional de Delegados de la Federación Obrera de la Industria de la Carne y Afines, 1957-1958, 1959-1960.

Libro de actas de la Federación Obrera de la Industria de la Carne y afines autónoma, $\mathrm{N}^{0} 11942-1946$.

\section{Bibliografía}

Alvira, Pablo, “¿Historia vs. Teoría? Epistemología y Ciencia Histórica en la Polémica Thompson- Althusser, Revista Historia Actual.8 (2010): 141-152.

Barrios Pintos, Aníbal, Reyes Abadie, Washington.Los barrios de Montevideo, El Cerro, Pueblo Victoria (La Teja) y barrios aledaños. Montevideo: IMM, 1994.

Buxedas, Martín. La Industria frigorífica en el Río de la Plata (1959-1971). Buenos Aires: CLACSO, Consejo Latinoamericano de Ciencias Sociales, 1983.

Bonetti, Juan Pablo.La Marcha del Hambre ¿Una historia enterrada, silenciada o escondida?. Uruguay: Tradinco SA, 2016.

Bonino Gayoso, Nicolás, y García Repetto, Ulises.Protección frente al desempleo estacional y bolsas de trabajo en Uruguay (1944-1979). Montevideo: Instituto de Economía, Serie Documentos de Trabajo, 2013. 
Camou, María Magdalena, "Estancamiento productivo y relaciones de trabajo en el Frigorífico Swift de Montevideo, 1911- 1957", Boletín de Historia Económica. Año VIII, $\mathrm{N}^{\circ} 9$ (2010).

Cocchi, Angel; Frega, Ana; Nahum, Benjamín, y Trochon, Yvette.Historia Uruguaya, Crisis política y recuperación económica 1930-1958. Montevideo: Banda Oriental, 2011.

Cores, Hugo.Aporte a la historia del movimiento obrero uruguayo, Tomo I, Las luchas de los gremios solidarios (1947-1952) Neo-batllismo, protesta social y Fuerzas Armadas. Montevideo: Banda Oriental, 1989.

Costabile, Daniel y Errandonea, Alfredo.Sindicato y Sociedad en el Uruguay. Montevideo: Fundación de Cultura Universitaria, 1969.

Dominzain, Susana (coord.), Ferreira, Pablo, Sosa, Álvaro, y García, Lorena. Así se forjó la historia,acción sindical e identidad de los trabajadores metalúrgicos en Uruguay. Montevideo: Editorial Primero de Mayo, 2006.

González Sierra, Yamandú. Cronología histórica del movimiento sindical uruguayo: Hechos, resoluciones políticas y eventos sindicales, 1870-1984. Montevideo: CIEDUR, Serie Documentos de Trabajo 58, 1989.

Hobsbawm, Eric.Política para una izquierda racional. Barcelona: Editorial Critica, 2016.

Lobato, Mirta Zaida.La vida en las fábricas, Trabajo, protesta y política en una comunidad obrera, Berisso (1904-1970),Buenos Aires: Editorial Prometeo, 2001.

Leibner, Gerardo. Camaradas y compañeros, una historia política y social de los comunistas en Uruguay. Montevideo: Trilce, 2011.

Malagraba, José Pedro. Mi vida, 68 años ininterrumpidos en la Industria (1925-1993) un ejemplo de "SelfMade Man". Montevideo: Austral, 1993.

Porrini, Rodolfo, "Memoria Histórica e historias de bancarios y 'friyeros". Historia y Memoria del mundo del trabajo. Rodolfo Porrini (comp.). Montevideo: Universidad de la República, 2004.

Porrini, Rodolfo, "Experiencia e identidad de la nueva clase obrera uruguaya: la huelga frigorífica (montevideana) de enero de 1943”, História UNISINOS 6, (2002), 63-96.

Poy, Lucas. Los orígenes de la clase obrera argentina, huelgas, sociedades de resistencia y militancia política en Buenos Aires, 1988-1896.Buenos Aires: Imago Mundi, 2014.

Rodríguez, Héctor.Nuestros sindicatos (1865-1965. Montevideo: Biblioteca sindical, Centro Estudiantes de Derecho, 1966.

Rodríguez, Universindo y otros. El sindicalismo uruguayo a 40 años del congreso de unificación. Montevideo: Santillana, 20016.

Thompson, E.P.La formación histórica de la clase obrera, Inglaterra 1780-1832, tomo I. Barcelona: Editorial Laia, 1977. 